\title{
Intestinal metaplasia in endoscopic biopsy specimens of gastric mucosa
}

\author{
GA ROTHERY, DW DAY \\ From the Department of Pathology, University of Liverpool, Liverpool
}

SUMMARY A total of 1412 consecutive cases of endoscopic gastric biopsy, carried out over a four year period, were reviewed and specimens were examined histochemically to determine the prevalence of intestinal metaplasia and its variants. Three types were characterised: complete intestinal metaplasia and two classes of incomplete intestinal metaplasia (type IIa and type IIb) depending on the absence or presence, respectively, of sulphomucins within mucin secreting columnar cells. Type IIb intestinal metaplasia was significantly more common in patients with gastric carcinoma $(\mathrm{p}<0.001)$ and in those with dysplasia $(\mathrm{p}<0.001)$ than in patients with benign gastric pathology. No such association was found with either type I or type IIa intestinal metaplasia. In addition to those present in the columnar cells of type IIb intestinal metaplasia, sulphomucins were also commonly found in goblet cells of all three types of metaplasia. The presence of sulphomucins in goblet cells, however, was not significantly associated with gastric carcinoma or dysplasia. The significance of the different types of intestinal metaplasia in relation to the pathological findings is discussed.

Epidemiological ${ }^{12}$ and morphological ${ }^{3-5}$ studies have shown that there is an association between intestinal metaplasia and gastric carcinoma, and it has been considered by many to be a possible marker of premalignant change. Intestinal metaplasia is also a common finding in benign disease of the stomach, however, and recent studies have therefore been directed at identifying variants of intestinal metaplasia which may have a more specific association with gastric carcinoma. ${ }^{6-12}$

On the basis of morphological and histochemical studies several variants of intestinal metaplasia have been described, and these findings have been supported by the results of enzyme histochemistry, ${ }^{1314}$ immunofluorescence, ${ }^{15}$ and ultrastructural examination. ${ }^{16-18}$ Although there is some variation in the classification of these subtypes of intestinal metaplasia according to different authors, two main groups are identifiable: complete intestinal metaplasia, which is morphologically similar to epithelium of the small bowel, and incomplete intestinal metaplasia, which shows intermediate features of both gastric and small bowel epithelium. Both groups can be further characterised by the presence

Accepted for publication 5 February 1985 or absence of large intestinal enzymes and mucins (o-acylated sialomucins and sulphomucins).

Several recent studies show that the presence of sulphated mucins in intestinal metaplasia has a closer association with gastric carcinoma than intestinal metaplasia in general..$^{6101214}$ This being the case, its presence in endoscopic biopsy material might serve as an important marker indicating the need for careful follow up of the patient. The aim of this investigation was to determine the prevalence of intestinal metaplasia and its variants in endoscopic biopsy specimens and to assess the significance of sulphated mucins in intestinal metaplasia in relation to different gastric diseases.

\section{Material and methods}

In the four year period between January 1980 and December 1983 a total of 1465 upper gastrointestinal endoscopies with gastric biopsy were carried out at the Royal Liverpool Hospital. Of these, 92 were repeat examinations, but for the purposes of the present study biopsies from each endoscopy were treated as an individual case. The histology of 1412 cases was reviewed; in the remaining 53 cases material was unavailable for examination and these were excluded. In each case haematoxylin and eosin 
Table 1 Histological findings and prevalence of intestinal metaplasia

\begin{tabular}{|c|c|c|c|c|c|c|c|}
\hline & $\begin{array}{l}\text { Total } \\
\text { no of } \\
\text { cases }\end{array}$ & Normal & $\begin{array}{l}\text { Chronic } \\
\text { gastritis }\end{array}$ & $\begin{array}{l}\text { Benign } \\
\text { ulcer }\end{array}$ & $\begin{array}{l}\text { Gastric } \\
\text { dysplasia }\end{array}$ & $\begin{array}{l}\text { Gastric } \\
\text { carcinoma }\end{array}$ & Other \\
\hline \multirow{3}{*}{$\begin{array}{l}\text { No of cases studied (\%) } \\
\text { No of cases of intestinal } \\
\text { metaplasia (\%) } \\
\% \text { of intestinal metaplasia } \\
\text { in each group }\end{array}$} & 1412 & $182(13 \%)$ & $618(44 \%)$ & $441(31 \%)$ & $30(2 \%)$ & $135(10 \%)$ & $6(<1 \%)$ \\
\hline & 524 & $0(0 \%)$ & $273(52 \%)$ & $169(32 \%)$ & $22(4 \%)$ & $60(11 \%)$ & $0(0 \%)$ \\
\hline & $37 \%$ & $0 \%$ & $44 \%$ & $38 \%$ & $73 \%$ & $44 \%$ & $0 \%$ \\
\hline
\end{tabular}

stained sections, cut at three different levels, were available for review together with an alcian blue (pH 2.5)/periodic acid Schiff stained section of the middle level. The alcian blue/periodic acid Schiff method distinguishes between neutral and acid mucins, which are stained red and blue respectively.

In each case the number of biopsy specimens received was noted, as were the histological sites and the pathological changes. The site was categorised as cardia, body, transitional, antral, or unknown, and the pathological changes were classified as normal, chronic gastritis (superficial gastritis and chronic atrophic gastritis), benign gastric ulcer (endoscopic or histological evidence of ulceration in the absence of dysplastic or malignant features), gastric dysplasia, and gastric carcinoma. The presence of intestinal metaplasia was noted together with a semiquantitative assessment of its extent within the tissue section. This was graded as focal (single gland or focus); moderate (less than one third of the biopsy specimen); extensive (more than one third of the biopsy specimen). In those cases in which intestinal metaplasia was identified a high iron diamine and alcian blue ( $\mathrm{pH} 2.5$ ) staining technique ${ }^{20}$ was carried out, using unstained spare sections which were available in most cases. This method distinguishes between sulphated (sulphomucins) and nonsulphated acidic mucins (sialomucins), which are stained brown-black and blue respectively. The intensity of the staining reaction was subjectively graded as: + (trace only) and ++ (strongcorresponding to the staining reaction of the colonic control).

Using both morphological and histochemical criteria, the cases of intestinal metaplasia were classified into three types ${ }^{19}$ :
1 Complete intestinal metaplasia (type I) resembles small intestinal epithelium (although villi are seldom well developed) with goblet cells secreting predominantly non-sulphated acid mucins and adjacent absorptive columnar cells showing well developed brush borders. The presence of Paneth cells is a further characteristic feature of this type of intestinal metaplasia, although they are not always found.

2 Incomplete intestinal metaplasia (type IIa) shows intermediate features of both gastric and small intestinal epithelia, with goblet cells secreting predominantly non-sulphated acid mucins and adjacent columnar mucous cells secreting mainly neutral mucins. Mature absorptive cells are not present.

3 Incomplete intestinal metaplasia (type IIb) is characterised by the presence of sulphomucins in columnar mucous cells adjacent to goblet cells secreting acid mucins, which may be sulphated or nonsulphated. Although this type appears similar to type IIa intestinal metaplasia on haematoxylin and eosin staining, there are usually morphological differences which facilitate distinction between the two: in type IIb intestinal metaplasia the epithelium appears hyperplastic with increased epithelial cell height and there is distortion and branching of the metaplastic glands.

In addition to classifying the cases of intestinal metaplasia into these three groups, they were also divided into either sulphomucin negative or sulphomucin positive intestinal metaplasia on the basis of any positive staining for sulphomucins, irrespective of the site of secretion or the type of intestinal metaplasia present. In each case of sulphomucin positive intestinal metaplasia the site and intensity of staining reaction and type of intestinal metaplasia

Table 2 Distribution of biopsy sites (shown as percentages) in the study group and in intestinal metaplasia and its subtypes

\begin{tabular}{|c|c|c|c|c|c|c|}
\hline & \multirow[t]{2}{*}{ All cases } & \multirow{2}{*}{$\begin{array}{l}\text { All cases } \\
\text { with intestinal } \\
\text { metaplasia }\end{array}$} & \multicolumn{3}{|c|}{ Types of intestinal metaplasia } & \multirow{2}{*}{$\begin{array}{l}\text { All sulphomucin } \\
\text { positive intestinal } \\
\text { metaplasia }\end{array}$} \\
\hline & & & Type I & Type IIa & Type IIb & \\
\hline $\begin{array}{l}\text { Antrum } \\
\text { Transitional } \\
\text { Body } \\
\text { Cardia } \\
\text { Unknown }\end{array}$ & $\begin{array}{r}52 \\
6 \\
28 \\
7 \\
7\end{array}$ & $\begin{array}{r}68 \\
4 \\
15 \\
9 \\
4\end{array}$ & $\begin{array}{r}73 \\
5 \\
12 \\
7 \\
3\end{array}$ & $\begin{array}{r}80 \\
1 \\
5 \\
13 \\
1\end{array}$ & $\begin{array}{r}74 \\
0 \\
4 \\
15 \\
7\end{array}$ & $\begin{array}{r}72 \\
3 \\
8 \\
15 \\
2\end{array}$ \\
\hline
\end{tabular}


Table 3 Mean age and male to female ratio in the study group and in intestinal metaplasia and its subtypes

\begin{tabular}{|c|c|c|c|c|c|c|}
\hline & \multirow{2}{*}{$\begin{array}{l}\text { All } \\
\text { subjects }\end{array}$} & \multirow{2}{*}{$\begin{array}{l}\text { All subjects } \\
\text { with intestinal } \\
\text { metaplasia }\end{array}$} & \multicolumn{3}{|c|}{ Types of intestinal metaplasia } & \multirow{2}{*}{$\begin{array}{l}\text { Sulphomucin } \\
\text { positive intestinal } \\
\text { metaplasia }\end{array}$} \\
\hline & & & Type I & Type IIa & Type IIb & \\
\hline $\begin{array}{l}\text { Male to female ratio } \\
\text { Mean age }(y r) \pm S D\end{array}$ & $\begin{array}{l}1 \cdot 3 \\
59 \pm 16\end{array}$ & $\begin{array}{l}1 \cdot 5 \\
64 \pm 12\end{array}$ & $\begin{array}{l}1 \cdot 6 \\
64 \pm 12\end{array}$ & $\begin{array}{l}1.4 \\
65 \pm 11\end{array}$ & $\begin{array}{l}1 \cdot 4 \\
68 \pm 11\end{array}$ & $\begin{array}{l}1 \cdot 7 \\
66 \pm 12\end{array}$ \\
\hline
\end{tabular}

were noted.

Statistical evaluation was performed using the $\chi^{2}$ test and Fisher's exact probability test.

\section{Results}

An average of 3.5 biopsy specimens was received for each of the 1412 cases examined, of which $53 \%$ were antral type gastric mucosa, $28 \%$ were body, $6 \%$ were transitional, and $7 \%$ were cardiac. In the remaining $6 \%$ of cases it was not possible to identify the biopsy site. Table 1 shows the distribution of histological findings in the series as a whole and also the prevalence of intestinal metaplasia within each of the disease categories. The six unclassified cases comprised four cases of non-Hodgkin's lymphoma, one case of gastric carcinoid, and one case of smooth muscle tumour.

Intestinal metaplasia, in one or more biopsies, was present in $37 \%$ of all the cases examined, and when compared with the whole series it was relatively more common in antral mucosa and less common in body mucosa (Table 2). No correlation was found between the extent of intestinal metaplasia in the biopsy specimens and the nature of the lesion. Intestinal metaplasia was a common finding in both benign and malignant lesions, but its prevalence was significantly higher $(\mathrm{p}<0.001)$ in dysplastic biopsies than in those showing benign disease (Table 1). Surprisingly, the prevalence of intestinal metaplasia in gastric carcinoma showed no such significant difference. This may be due partly to the fact that of the 135 cases of carcinoma identified $28(21 \%)$ of the specimens consisted of malignant tissue only.

Table 3 shows that while no appreciable difference was found between the male to female ratio in the whole series and in the group with intestinal metaplasia, the mean age was significantly higher ( $p$ $<0.001)$ in the latter group.

\section{TYPES OF INTESTINAL METAPLASIA}

Of the 524 cases of intestinal metaplasia, 489 were 

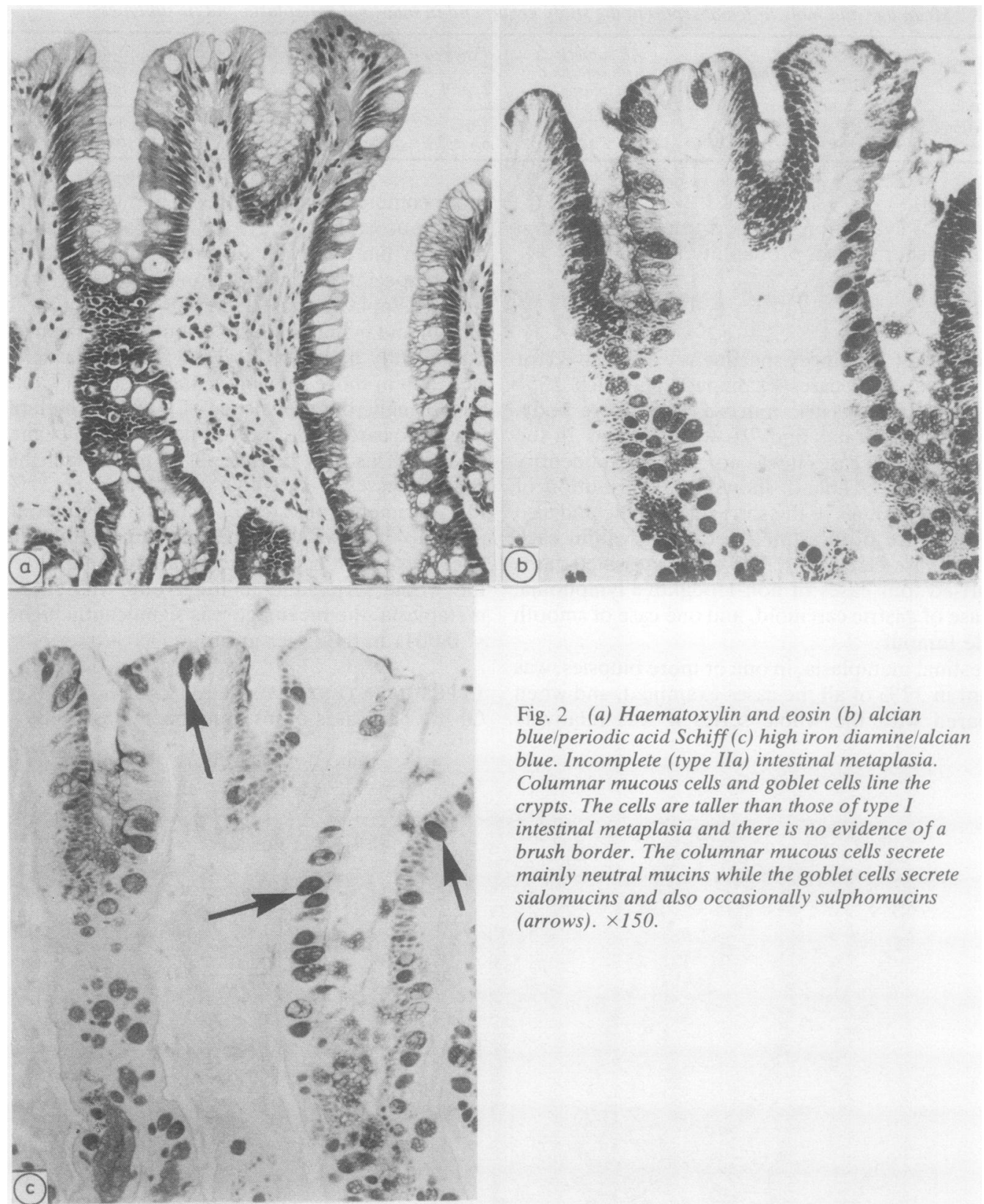

Fig. 2 (a) Haematoxylin and eosin (b) alcian blue/periodic acid Schiff (c) high iron diamine/alcian blue. Incomplete (type IIa) intestinal metaplasia. Columnar mucous cells and goblet cells line the crypts. The cells are taller than those of type I intestinal metaplasia and there is no evidence of a brush border. The columnar mucous cells secrete mainly neutral mucins while the goblet cells secrete sialomucins and also occasionally sulphomucins (arrows). $\times 150$. 

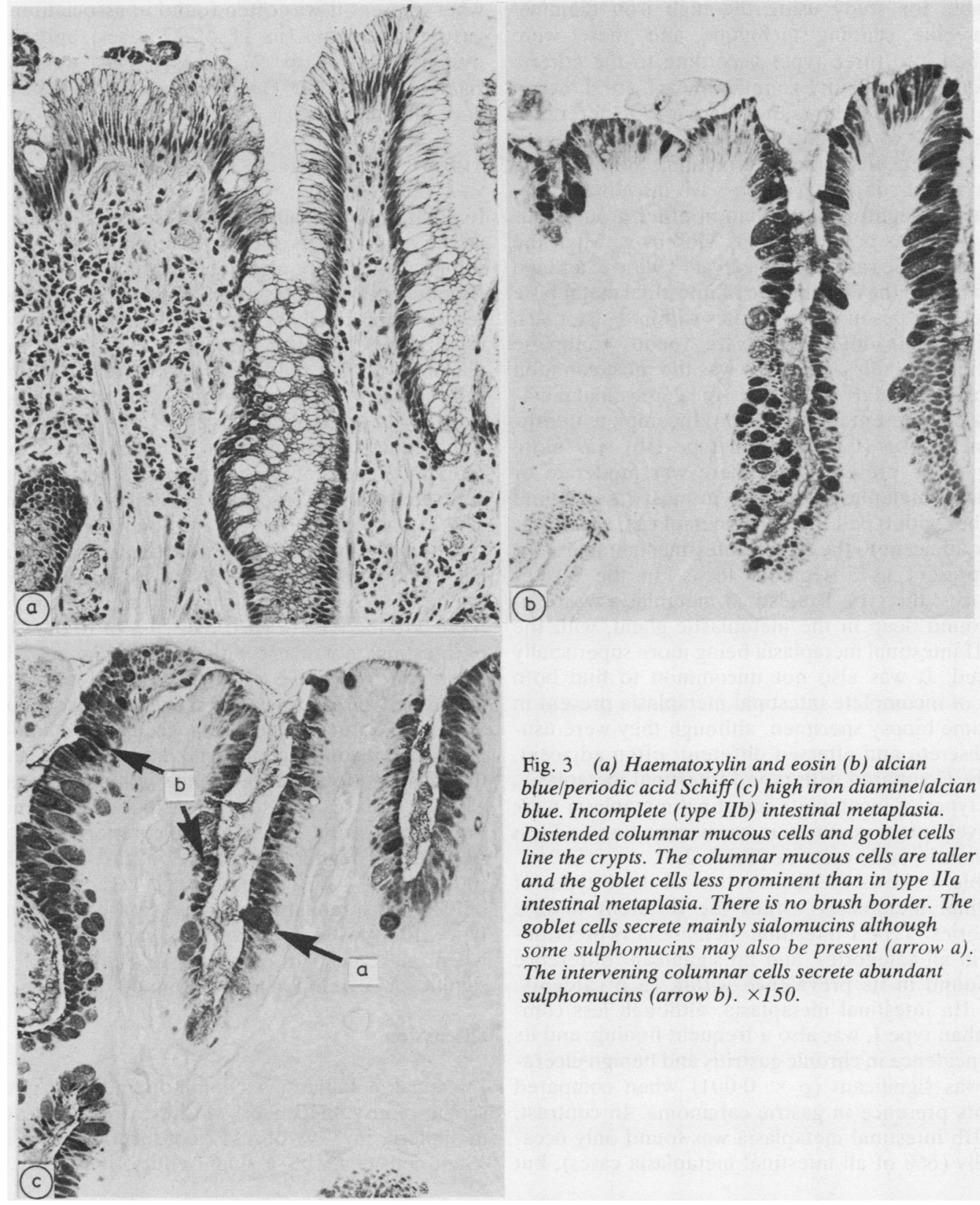

Fig. 3 (a) Haematoxylin and eosin (b) alcian blue/periodic acid Schiff (c) high iron diamine/alcian blue. Incomplete (type IIb) intestinal metaplasia. Distended columnar mucous cells and goblet cells line the crypts. The columnar mucous cells are taller and the goblet cells less prominent than in type IIa intestinal metaplasia. There is no brush border. The goblet cells secrete mainly sialomucins although some sulphomucins may also be present (arrow a). The intervening columnar cells secrete abundant sulphomucins (arrow b). $\times 150$. 
available for study using the high iron diamine/ alcian blue staining technique and these were classified into three types according to the criteria previously described. Examples of each are shown in Figs. 1-3. Table 3 shows that there is little difference in the male to female ratio between the different types of intestinal metaplasia and, although the mean age of subjects with type IIb intestinal metaplasia was slightly higher than in other groups, this difference was not significant. Moreover, when the male to female ratios and mean ages were examined in relation to the distribution of intestinal metaplasia and its subtypes in different sites within the stomach no significant differences were found. Complete intestinal metaplasia (type I) was the most common finding, particularly when only focal intestinal metaplasia was present in the section. Incomplete intestinal metaplasia (type IIa and type IIb) was more likely to be present when there was moderate or extensive metaplasia and was, in most cases, found together with type I intestinal metaplasia, which was either adjacent to the type II intestinal metaplasia or was present as a separate focus. In the former instances, the type I intestinal metaplasia was usually found deep in the metaplastic gland, with the type II intestinal metaplasia being more superficially situated. It was also not uncommon to find both types of incomplete intestinal metaplasia present in the same biopsy specimen, although they were usually discrete and affected different, often adjacent, glands. Compared with type I intestinal metaplasia, both types of incomplete intestinal metaplasia were relatively more common in cardiac mucosa and less common in body mucosa (Table 2).

Table 4 shows the distribution of these types of intestinal metaplasia within the different disease categories. Type I intestinal metaplasia is predominant in all categories, and no significant difference was found in its prevalence within each category. Type IIa intestinal metaplasia, although less common than type I, was also a frequent finding, and its high incidence in chronic gastritis and benign ulceration was significant $(p<0.001)$ when compared with its presence in gastric carcinoma. In contrast, type IIb intestinal metaplasia was found only occasionally ( $6 \%$ of all intestinal metaplasia cases), but when present it was often found in association with gastric carcinoma (in 11 of 27 cases) and gastric dysplasia (in 7 of 27 cases). This was highly significant $(p<0.001)$ when compared with its presence in benign lesions.

\section{ALL SULPHOMUCIN POSITIVE INTESTINAL METAPLASIA}

In addition to the sulphomucins secreted by the columnar mucous cells of type IIb intestinal metaplasia, sulphomucins were also detected in type I and type IIa intestinal metaplasia (in $44 \%$ and $59 \%$ of cases, respectively). In these cases the sulphomucins were usually present within the goblet cells of the metaplastic crypt, but they were also found in columnar cells adjacent to the metaplastic areas and in glands deep to the metaplastic crypts. Table 2 shows that sulphomucin positivity was found relatively more often in biopsies of cardiac mucosa when compared with the group of intestinal metaplasia as a whole. There was considerable variation in the staining reaction of sulphomucins (except in type IIb intestinal metaplasia, in which all but two cases showed strong ++ reactions), but this did not appear to be related to the type of gastric disease or to the extent of intestinal metaplasia within the specimen. All the sulphomucin positive cases of intestinal metaplasia, including type IIb intestinal metaplasia, were considered as a further separate group (sulphomucin positive intestinal metaplasia) and Table 4 shows their distribution and prevalence within the different gastric disease categories. Although commonly found in gastritis and benign ulceration, there is a significantly higher prevalence in gastric dysplasia $(0.02<p<0.01)$ and gastric carcinoma $(p<$ $0.001)$. This appears to be due to the inclusion of type IIb intestinal metaplasia, however, because when all type IIb cases are excluded no such significant correlation can be found.

\section{Discussion}

Intestinal metaplasia is a common finding in gastroscopic biopsy specimens: we have found intestinal metaplasia in $37 \%$ of 1412 consecutive cases and, when considered as a single entity, it is clearly of

Table 4 Distribution of types of intestinal metaplasia

\begin{tabular}{|c|c|c|c|c|c|}
\hline & \multirow{2}{*}{$\begin{array}{l}\text { No of cases of } \\
\text { intestinal metaplasia which } \\
\text { could be further classified }\end{array}$} & \multicolumn{3}{|c|}{ Types of intestinal metaplasia } & \multirow{2}{*}{$\begin{array}{l}\text { Sulphomucin } \\
\text { positive intestina } \\
\text { metaplasia }\end{array}$} \\
\hline & & Type I & Type IIa & Type IIb & \\
\hline $\begin{array}{l}\text { Chronic gastritis } \\
\text { Benign gastric ulcer } \\
\text { Gastric dysplasia } \\
\text { Gastric carcinoma } \\
\text { Total }\end{array}$ & $\begin{array}{r}265 \\
155 \\
17 \\
52 \\
489\end{array}$ & $\begin{array}{c}245(92 \%) \\
138(89 \%) \\
17(100 \%) \\
47(90 \%) \\
447(91 \%)\end{array}$ & $\begin{array}{r}81(31 \%) \\
65(42 \%) \\
7(41 \%) \\
10(19 \%) \\
163(33 \%)\end{array}$ & $\begin{aligned} & 4(2 \%) \\
& 5(3 \%) \\
& 7(41 \%) \\
& 11(21 \%) \\
& 27(6 \%)\end{aligned}$ & $\begin{array}{r}106(40 \%) \\
71(45 \%) \\
12(71 \%) \\
38(73 \%) \\
227(46 \%)\end{array}$ \\
\hline
\end{tabular}


little value as a marker of premalignant change. The heterogeneity of intestinal metaplasia has long been recognised, however, ${ }^{162122}$ and recently several variants have been reported. Several authors have suggested that some of these variants may have a special part to play in the histogenesis of gastric carcinoma. $^{781123}$

Incomplete forms of intestinal metaplasia have been described on the basis of mucin 6410 and enzyme ${ }^{13 / 4}$ histochemistry and ultrastructural studies. ${ }^{1718}$ Others have reported a colonic type of intestinal metaplasia by showing the presence of o-acylated sialomucins ${ }^{810}$ together with sulphomucins $^{12}$ within the metaplastic goblet cells. Heilmann and Hopker ${ }^{11}$ described an enterocolic metaplasia, in which sulphomucins are secreted and which appears to be similar to the type IIb intestinal metaplasia described by Jass ${ }^{19}$ and identified in this study.

In this study we have classified intestinal metaplasia into three groups as described by Jass ${ }^{19}$ : complete (type I) and two types of incomplete (type IIa and type IIb) intestinal metaplasia, depending on the presence or absence of sulphomucins in the mucous columnar cells. Type I intestinal metaplasia was a common finding in both benign and malignant gastric disease, and neither type I nor type IIa intestinal metaplasia showed any significant association with carcinoma. Indeed, type IIa intestinal metaplasia appeared to show a positive correlation with benign gastric pathology. In contrast, type IIb intestinal metaplasia, although found much less commonly, was often (41\% of type IIb intestinal metaplasia cases) present in association with gastric carcinoma and, when compared with its incidence in chronic gastritis and peptic ulceration, this appeared highly significant. These results are comparable with the findings of others ${ }^{1019}$ and support the suggestion that a variant of intestinal metaplasia showing appreciable sulphomucin secretion may be a premalignant lesion. ${ }^{611}$ Our results suggest, however, that type IIb intestinal metaplasia shows low sensitivity as a marker of neoplasia since it was present in only $21 \%$ of biopsies which contained both cancer and intestinal metaplasia. The incidence of this type of metaplasia is somewhat higher $(41 \%)$ in cases of gastric dysplasia and it is possible that destruction of areas of type IIb intestinal metaplasia by tumour growth may account for this difference. Inadequate sampling of tissue from the periphery of the tumour might be another explanation.

A further possibility is that type IIb intestinal metaplasia is involved in the histogenesis of only one particular subgroup of carcinomas. Several studies which have looked at intestinal metaplasia in gastrectomy specimens containing gastric carcinoma have reported a particular association between sul- phomucin positive variants of intestinal metaplasia and carcinomas showing intestinal differentiation when compared with diffuse gastric carcinomas. ${ }^{10-1219}$ Unfortunately, in this study, because of the possibility of sampling error which is inherent in the use of biopsy material, we thought that classification of gastric carcinoma into these two groups was not valid and we are therefore unable to confirm these findings. Of the 52 cases of gastric carcinoma in which intestinal metaplasia was present in the biopsy specimen, however, 23 gastrectomy specimens were available for examination. Of these carcinomas, 15 were classified as intestinal and eight as diffuse (using the criteria of Lauren ${ }^{24}$ ); it is of interest to note that in the biopsy material type IIb intestinal metaplasia was found only in association with intestinal carcinomas.

In addition to finding sulphomucins in columnar cells of type IIb intestinal metaplasia, we found that goblet cells of both complete and incomplete intestinal metaplasia often contained sulphomucins. When we looked at all sulphomucin positive cases of intestinal metaplasia we found that they accounted for almost half of all cases of intestinal metaplasia and were often present in benign lesions. Although sulphomucin positive intestinal metaplasia was more commonly seen in association with carcinoma, this appeared to be due to the inclusion of type IIb intestinal metaplasia cases. These results suggest that the detection of sulphomucins in goblet cells is of little assistance in the interpretation of intestinal metaplasia in gastric biopsy material. Sipponen et al in $1980^{7}$ reported a significant association between all sulphomucin positive intestinal metaplasia and gastric carcinoma using matched controls, but the sites of sulphomucin positivity were not defined, although, from the description given, goblet cell staining appeared to predominate.

Sulphomucins are occasionally present in trace amounts in normal gastric mucosa, where they may be found, together with sialomucins, in deep foveolar cells and mucous neck cells of the antrum and body and also in cardiac glands near the oesophago-gastric junction. ${ }^{625-27}$ Their function in normal gastric mucosa is unknown, but as the foveolar cells migrate to the surface acid groups are lost and the content of neutral mucins increases. ${ }^{27}$ It has been suggested that both metaplastic and normal pit cells originate from stem cells, in the deep pit or isthmus of the gastric gland, which have the capacity for multipotential differentiation. ${ }^{16}$ Furthermore, the sulphomucin secreting columnar cells of type IIb intestinal metaplasia are considered to be intermediate cells, with features of both gastric and intestinal epithelium, and represent partial differentiation of stem cells. ${ }^{141718}$ Their presence at the free 
mucosal surface in incomplete metaplasia may represent a step in a process of dedifferentiation. ${ }^{118}$ The frequent finding in this study of complete intestinal metaplasia deep to incomplete intestinal metaplasia within the same gland agrees with the experience of others. ${ }^{915}$ We suggest that incomplete intestinal metaplasia is an immature form of metaplasia which is usually replaced by complete intestinal metaplasia and that dedifferentiation to type IIb intestinal metaplasia, with intermediate cells secreting sulphomucins, may occur during the course of malignant transformation. In support of this is the finding that cells resembling intermediate cells and showing increased sulphomucin secretion are present within non-metaplastic epithelium adjacent to gastric carcinomas, ${ }^{26}$ in adenomatous polyps and the surrounding metaplastic mucosa, ${ }^{23}$ and in gastric carcinomas. ${ }^{172628}$

In this study, because of insufficient unstained sections for each case, we were unable to look for o-acylated sialomucins which are normally found only in colonic mucosa and are stained red by the periodate borohydride/potassium hydroxide/ periodic acid Schiff method. This would have been interesting because the significance of this type of colonic mucin in intestinal metaplasia is unclear; some workers have shown an association with gastric carcinoma ${ }^{812}$ while others have not found this to be the case..$^{1019}$

Although we, in common with others, have found a strong association between a variant of intestinal metaplasia-that is, type IIb intestinal metaplasia-and carcinoma, this does not exclude the possibility that this type of metaplasia represents a secondary reactive phenomenon to malignant transformation. We have also shown, however, that there is a selective association between type IIb intestina! metaplasia and gastric dysplasia, and this would appear to support the suggestion that this type of metaplasia may be precancerous. To determine whether this variant of intestinal metaplasia is indeed a true marker of premalignant change, prospective studies are required. Our results also show that sulphomucin secretion in sites other than in the columnar mucous cells of incomplete intestinal metaplasia does not appear to be associated with gastric carcinoma, and we believe, therefore, that it is important to emphasise the need for precise description of the site of sulphomucin positivity in further work in this field. Finally, while routine staining for sulphomucins in all gastric biopsy material is clearly not warranted, recognition of incomplete intestinal metaplasia is possible on haematoxylin and eosin and alcian blue/periodic acid Schiff stains and staining for sulphomucins in this smaller group-that is, about $15 \%$ of cases in this series-would enable the detection and careful follow up of those individuals with type IIb intestinal metaplasia.

We thank $\mathrm{Mr} \mathrm{J}$ Massey for technical assistance, $\mathrm{Mr}$ A Williams for the photography, and Miss C Youd for secretarial help.

\section{References}

Imai T, Kubo T, Watanabe $\mathrm{H}$. Chronic gastritis in Japanese with reference to high incidence of gastric carcinoma. J Natl Cancer Inst 1971;47:179-95.

${ }^{2}$ Correa P, Cuello C, Duque E. Carcinoma and intestinal metaplasia of the stomach in Colombian migrants. $J$ Natl Cancer Inst 1970;44:297-306.

${ }^{3}$ Morson BC. Carcinoma arising from areas of intestinal metaplasia in the gastric mucosa. Br J Cancer 1955;9:377-85.

${ }^{4}$ Morson BC. Intestinal metaplasia of the gastric mucosa. $\mathrm{Br} \mathrm{J}$ Cancer 1955;11:365-76.

s Sipponen P, Kekki M, Siurala M. Age-related trends of gastritis and intestinal metaplasia in gastric carcinoma patients and in controls representing the population at large. Br J Cancer 1984;49:521-30.

- Jass JR, Filipe MI. A variant of intestinal metaplasia associated with gastric carcinoma: a histochemical study. Histopathology 1979;3:191-9.

' Sipponen P, Seppala K, Varis K, et al. Intestinal metaplasia with colonic type sulphomucins in the gastric mucosa; its association with gastric carcinoma. Acta Pathol Microbiol Scand 1980;88:217-24

${ }^{8}$ Teglbjaerg PS, Nielson HO. 'Small intestinal type' and 'colonic type' intestinal metaplasia of the human stomach. Acta Pathol Microbiol Scand 1978;86:351-5.

" Iida F, Kusama J. Gastric carcinoma and intestinal metaplasia: significance of types of intestinal metaplasia upon development of gastric carcinoma. Cancer 1982;50:2854-8.

${ }^{10}$ Segura DI, Montero C. Histochemical characterization of different types of intestinal metaplasia in gastric mucosa. Cancer 1983;52:498-503.

" Heilmann KL, Hopker WW. Loss of differentiation in intestinal metaplasia in cancerous stomachs. A comparative morphologic study. Pathol Res Pract 1979;164:249-58.

${ }^{12}$ Lei DN, Yu JY. Types of mucosal metaplasia in relation to the histogenesis of gastric carcinoma. Arch Pathol Lab Med 1984; 108: $220-4$.

${ }^{13}$ Kawachi T, Kurisu M, Numanyu N, Sasajima K, Sano T, Sugimura T. Precancerous changes in the stomach. Cancer Res 1976;36:2673-7.

${ }^{14}$ Matsukura N, Suzuki K, Kawachi T, et al. Distribution of marker enzymes and mucin in intestinal metaplasia in human stomach and relation of complete and incomplete types of intestinal metaplasia to minute gastric carcinomas. J Natl Cancer Inst 1980;65:231-40.

is Ma J, De Boer WGM, Nayman J. Intestinal mucinous substances in gastric intestinal metaplasia and carcinoma studied by immunofluorescence. Cancer 1982;49:1664-7.

${ }^{16}$ Ming SC, Goldman H, Freiman DG. Intestinal metaplasia and histogenesis of carcinoma in human stomach. Cancer 1967;20: 1418-29.

${ }_{17}$ Goldman H, Ming SC. Fine structure of intestinal metaplasia and adenocarcinoma of the human stomach. Lab Invest 1968; 18:203-10.

${ }^{18}$ Stockton M, McColl I. Comparative electron microscopic features of normal intermediate and metaplastic pyloric epithelium. Histopathology 1983; 7:859-71.

19 Jass JR. Role of intestinal metaplasia in the histogenesis of gastric carcinoma. J Clin Pathol 1980;33:801-10. 
${ }^{20}$ Spicer SS. Diamine methods for differentiating mucosubstances histochemically. J Histochem Cytochem 1965;13:211-34.

${ }^{21}$ Stemmermann GN, Hayashi T. Intestinal metaplasia of the gastric mucosa: a gross and microscopic study of its distribution in various disease states. $J$ Natl Cancer Inst 1968;41:627-34.

${ }^{22}$ Tarpila S, Telkka A, Siurala M. Ultrastructure of various metaplasias of the stomach. Acta Pathol Microbiol Scand 1969;77: 187-95.

23 Jass JR, Filipe MI. Sulphomucins and precancerous lesions of the human stomach. Histopathology 1980;4:271-9.

${ }^{24}$ Lauren P. The two main histological types of gastric carcinoma: diffuse and so-called intestinal type carcinoma. An attempt at a histoclinical classification. Acta Pathol Microbiol Scand 1965;64:31-49.
${ }^{25}$ Lev $R$. The mucin histochemistry of normal and neoplastic gastric mucosa. Lab lnvest 1966; 14:2080-100.

${ }^{26} \mathrm{Gad}$ A. A histochemical study of human alimentary tract mucosubstances in health and disease. $\mathrm{Br} J$ Cancer 1969;23:52-63.

${ }^{27}$ Goldman H, Ming SC. Mucins in normal and neoplastic gastrointestinal epithelium. Arch Pathol Lab Med 1968;85:580-6.

${ }^{2 \pi}$ Montero C, Segura DI. Retrospective histochemical study of mucosubstances in adenocarcinomas of the gastrointestinal tract. Histopathology 1980;4:281-91.

Requests for reprints to: Dr G Rothery, Department of Pathology, Duncan Building, Royal Liverpool Hospital, Liverpool L7 8XW, England. 